\begin{tabular}{c} 
Volume and Issues Obtainable at Center for Sustainability Research and Consultancy \\
Journal of Business and Social Review in Emerging Economies \\
ISSN: 2519-089X (E): 2519-0326 \\
Volume 5: No. 1, June 2019 \\
CSRᄃ \\
Journal homepage: www.publishing.globalcsrc.org/jbsee \\
\hline
\end{tabular}

\title{
Psychosocial Adjustment Among Abused Children in Residential Care
}

\author{
${ }^{1}$ Ropizah Rohani, ${ }^{2}$ Zakiyah Jamaluddin, ${ }^{3}$ Abd Razak Abd Manaf \\ ${ }^{1}$ Awang Had Salleh Graduate School of Social Development, Universiti Utara Malaysia, Email adress: \\ ainulomeimama@gmail.com \\ ${ }^{2}$ Lecturer, School of Social Development, Universiti Utara Malaysia, Email adress: zakiyah@uum.edu.my \\ ${ }^{3}$ Lecturer, School of Social Development, Universiti Utara Malaysia, Email adress: a.razak@uum.edu.my
}

\begin{tabular}{l}
\multicolumn{1}{c}{ ARTICLE DETAILS } \\
\hline History \\
Revised format: May 2019 \\
Available Online: June 2019 \\
\hline Keywords \\
Abused Children, Residential, \\
Psychosocial
\end{tabular}

JEL Classification:

$J 13, J 19$

\section{ABSTRACT}

Purpose: The purpose of this paper is to propose a conceptual framework on the key determinant of psychosocial adjustments in terms of behavior, social, emotion and mental health among abused children in residential care.

Methodology: This research is designed as a qualitative study approach. Case study method is used to explore primer data which emphasis on psychosocial adjustments and narrative data from the perspective of children living in residential care. Research participants consist of children living in welfare care in Perlis, Malaysia and the respective staffs. Findings: Chronic abuse will leave harmful effects on various aspects of the children's development. Abuse will also affect one's emotional wellness and balance which will further impact the psychosocial stability of an individual in adulthood. Most victims will not be able to develop a sense of belonging and necessary social skills which eventually will lead to these individuals not being able to socialize in the real life situations. Therefore the placements of these children in a safe environment so as to ensure better care and protection must be given proper attention. The transition of caregivers from parents to the welfare centre will affect these children too. They need time to build trust and relationship so that they can feel comfortable to share their experiences and also emotions. Caregivers in the institutions are the main elements in ensuring the quality and effectiveness of educational programmes of the centres.

Practical Implications: Rehabilitation programme is needed to balance the children's needs based on age and ability to give the residents chances to practice skills and also learn to adapt to the outside world.

Social Implications - The institutions should provide condusive life experiences as they have a large impact to the success of the rehabilitation process. In addition, good quality services in fulfilling the children's need will assure healthy development of the children and their ability to adapt well to the outside world

(C) 2019 The authors, under a Creative Commons AttributionNonCommercial 4.0

Corresponding author's email address: ainulomeimama@gmail.com

Recommended citation: Rohani, R., Jamaluddin, Z. and Manaf, A. R. A. (2019). Psychosocial Adjustment Among Abused Children in Residential Care. Journal of Business and Social Review in Emerging Economies, 5 (1), 175-180 
DOI: $10.26710 /$ jbsee.v5i1.521

\section{Introduction}

Child abuse involves direct actions which are unsuitable or lead to physical hurt towards children by adults or caregivers and eventually will effect their development emotionally, socially and psychologically (Koizumi \& Takagishi, 2014). There are various forms of child abuse be it physical, sexual, emotional and abandonment (Bruskas \& Tessin, 2013). Child abuse is complex and complicated predicament to be diagnosed to determine whether it is an accident, illness or intentional hurt (Alavi, Amin, Subhi, Mohamad, \& Sarnon, 2012). Child abuse is not restricted to the child's situation alone but it involves those who have been trusted to care for the child such as helpers, relatives, neighbours or even teachers (Md.Akhir et al., 2012; United Nations Children's Fund Malaysia, 2010).

According to the Welfare Department Statistics or Jabatan Kebajikan Masyarakat (JKM) (2014), reported cases of child abuse indicate worrying figure for the period of 2010 to 2013 which is 14,662 cases. The victims of abuse will be rescued and if the children need care and protection, actions will be taken according to the Children Act 2001 as follows (Jabatan Kebajikan Masyarakat, 2015), (i) being placed in child home for three years or until the victims reaching the age of 18, or (ii) being put in the custody of a qualified and suitable caregivers for a period decided by the court under the supervision of a 'protector' (a welfare officer). According to the statistics released by the Welfare Department (2014), for the period of three years from 2012 to 2014, the total number of children needing protections has increased around four to seven percent. In the year 2012, a total of 3,831 cases were reported and have increased by 7.5 percent to 4,119 cases in 2013 . The cases further increased 4.3 percent to 4,295 cases in 2014.

\section{Problem Statement}

Although abuse cases in Malaysia are getting worse, studies on cases and victims are unpopular and difficult to find (Wahab, Tan, Marimuthu, Razali, \& Muhamad, 2013) especially those related to psychosocial adjustments studies involving victims of abuse are limited may be due to difficulties to access the respondents (Wahab et al., 2013). Very little information regarding life and roles of residential care are known in Malaysia (Raj \& Raval, 2013).

The main aim of setting up a protective institution is to educate, kick start behavioural changes and self perception and also to influence identity building (Raj \& Raval, 2013). The process should be carried out through various social pedagogic activities and approaches led by trained professionals such as social workers, teachers, counselors, special needs services and psychiatrics (Morton, 2015). However, children currently living in the residential care do not receive effective services from the mentioned group of professionals. Instead, they are placed in a special social environment together with children and adults, interacting and connecting daily (Glantz \& Gushwa, 2013). In the efforts to handle psychosocial challenges, the residents of residential care are more comfortable sharing problems and seeking supports from peers within the institutions as compared to the staffs of the institution (Abd. Manaf \& Mokhtar, 2013). This clearly indicates that children's development are not individually focused in the care and protective institutions. Hence, the children are facing difficulties in handling psychosocial adjustments when they are in an outside environment away from the care and protective institutions (Almas et al., 2015).

Limited knowledge regarding issues related to the residential care residents will create a stigma and negative images as from adults' persepctives, these children are categorized as troubled children (Chan, 2013). Inadequate primer data which covers psychosocial adjustment and narratives data from the residence perspectives are the loopholes that need to be explored. Limited information and data related to psychosocial development is a sign to the need of more attention and research in the area.

\section{Literature Review}

\subsection{Psychosocial Adjustment}

Psychosocial adjustment refers to one's ability to function and adapt successfully in fulfilling surrounding needs (Almas et al., 2015). Psychosocial needs are also pictured as stable mental health in various aspects such as personal contentment, family, satisfactory relationship, the ability to contribute to the community and acquiring positive social skills. One of the psychosocial adjustments concept is by looking at the individual being free from external or internal behavioural problems. To evaluate one's psychosocial situation is when the individual interact or communicate with surrounding people in a social situation (Renfree, Mcdermott, Nelson, Zeanah, \& Fox, 2015). 
In conclusion, psychosocial adjustments refer to a balance aspects of behavioural, emotional, cognitive and social domain (Almas et al., 2015;Renfree et al., 2015).

\subsection{Effects of Child's Abuse}

Chronic abuse give harmful effects in various aspects of the victim's life development especially children who face constant abuse at every development stage (Yampolskaya, Mowery, \& Dollard, 2014). Past and comtemporary studies have proven that children who suffer abuse and maltreatment since young will exhibit critical behavioural problems (Yampolskaya et al., 2014). The behavioural problems may occur externally or internally. Therefore, these behavioural problems are the main contributor towards the lack of social inclinations such as running away from home, displinary problems, deliquents, free sex and substances abuse(Morton, 2015).

Victims of abuse pose higher risks in having social problems due to low self effication, self concept, lack of stress management and problem solving. This situation leads to unhealthy development of self image and consequently leads to social such as being disruptive, withdrawal, low self esteem and insecurities in building relationships (Abd. Rahman et al., 2013). Previous studies have also linked negative social adjustment with personality problems which occur due to lack of social skills, interactions and communications especially with strangers. A few findings from previous studies also indicate that the aspect of problems in social adjustment will affect adjustment ability (Henrichon, 2016). To sum it up, most abuse victims are not able to develop sense of belonging and social skills needed and eventually caused them the inability to socialize in the real world.

Emotional problems caused by post traumatic stress will haunt the victims all their life (Abd. Manaf \& Mokhtar, 2013). Emotional probems are closely related to anxiety, depression and anger caused by the stress they experience. In accordance to studies conducted by local researchers, they reported that victims of sexual abuse experienced confusions, guilt, fear, self blaming, emotional and trapped with the incidents (Wahab et al., 2013). This clearly shows that the effects of abuse are really serious as they will disrupt emotional balance and well being which later affect the individuals' psychological stability into adulthood.

Among abuse issue chosen by researcher is mental health disorder. This is because abuse have been linked to severe mental health disorder throughout the life. Mental disorder is caused by the feeling of fear, disappointment, low self esstem, feeling of being threatened and repetitive memory of the incidents (Mokhtar, 2015). Severe mental disorder are shown by increased confusions, psychiatric problems like suicidal thoughts as indicated

\subsection{Care and Protective Institutions}

Children growing up in care and protective institutions need more than food, clothing and shelter. Instead they should be given more opportunities to build ties with adults in a surrounding which emphasizes the concept of family institutions (Nalasamy \& Ah, 2013). Building up good relationships between caregivers and residents are crucial as these influence teenagers' perceptions to be more tolerant in accepting rules. Strict and rigid rules are seen as a way to control and discipline children. Hence, most rehabilitation programmes in care and protective intsitutions are focused on behavior modifications to reduce naughtiness (Nalasamy \& Ah, 2013), as the main reasons for the children's placement are emotional and behavioural problems (Schmidt, Cunningham, Dalton, Powers, Geenen \& Orozco, 2013). Rigid, inconsistent and unclear rules (Saim et al., 2013) especially in reprimanding them (Abd. Manaf \& Mokhtar, 2013) would cause confusion to the children. However, these children see all forms of barriers and limitations imposed on them as a term of rigid rules and only for the benefits of the administrators.

The effectiveness of the placements of the children in care and protective instituions is often doubted as it leaves negative effects on the children (Schmidt et al., 2013). The children are affected in the aspects of health, education and difficulties in securing jobs when they leave the institutions. Teenagers living in these institutions also posses less encouraging opinions on life and prospects of the future as compared to the teens of the same ages in normal environment (Nalasamy \& Ah, 2013). Experiences living in residential care hve incited over socialization process due to sharing of amenities and sharing of love to fill up the hollowness existed (pseudo family), due to separation from family. Nevertheless, over socialization does not encourage positive learning pattern because the residents are prone to spending time doing none academic activities. However, the residents feel that negative attitude towards learning happens due to ineffective programmes, under qualified counselors, unappealing moral classes and outdated facilities. This situation usually puts these teens in the low academic achievements. 
The placement of young children at protective institutions have impacted their development as it is proven that they will face social problems when they reach their teens. This is due to the focus of the institutions is more towards fulfilling their physical needs as compared to social interactions (Nalasamy \& Ah, 2013). Apart from that, it is found that the care and protective institutions are using the same form of treatment on all residents without referring to the children background such as their admittance criteria (Yampolskaya et al., 2014) clinical report.

\section{Underpinning Theory}

Attachment theory is a collaboration between John Bowlby and Mary Ainsworth which tries to explain and measure babies responses when they are being separated from their mothers (Fonagy, 2018). Attachment theory is also known as psychosocial theory that explores human's experiences developed from the interactions between individual psychology and their environment. This consequently affects individuals psychosocial development throughout a lifetime (Fonagy \& Campbell, 2016). Previous studies indicate that intimacy with parents is closely related to a few teen's psychosocial adjustments such as behavioural probems, emotion, cognitive and school's. Researchers on psychology development theory have adopted attachment theory as the guidelines and framework to understand individual differences in emotional development and psychosocial functions and also teens' adjustment away from the family context (Soares et al., 2014).

\section{Framework}

Abuse that happen severe the ties with parents as primary caregivers. As the continuous step to continue care and protection, children are placed in residential care. The effects of separation from families and experiences of being abused leave marks on the aspects of behavior, emotions, cognitive, mental and social. Hence indirectly these situations disturb the stability of the children's psychosocial adjustments.

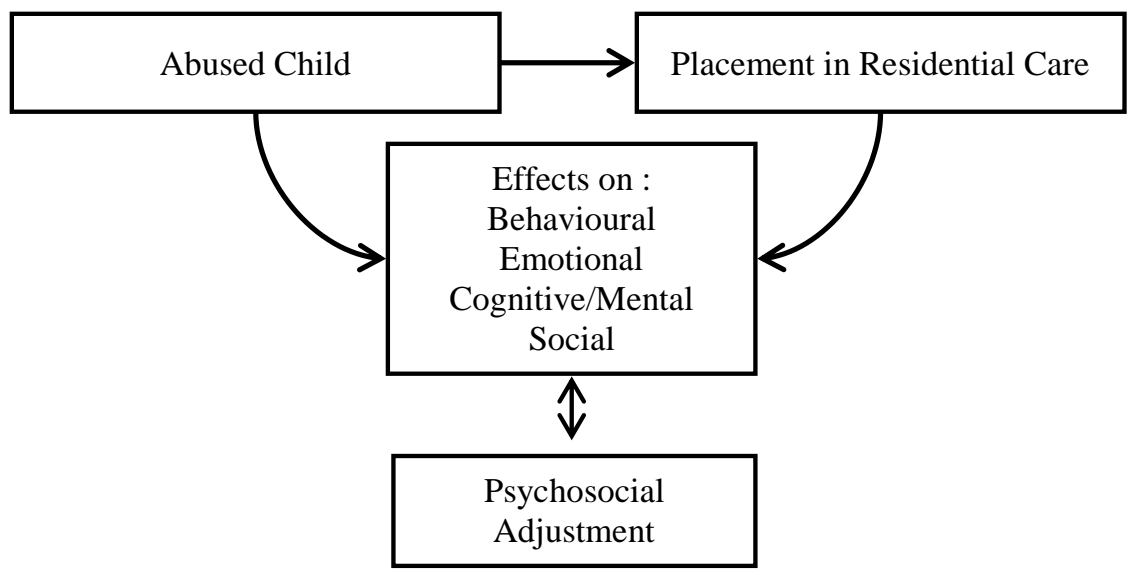

Figure 5.1: Research Framework

\section{Methodology}

This research is designed as a qualitative study approach. The researcher chooses case studies based on exploratory studies which requires deep understandings on psychosocial adjustments of residents in the protective institutions. Data collections are done through semi structured individuals and groups interviews. The location is Rumah KanakKanak (RKK) Arau, Perlis which is supervised by the Welfare Department of Malaysia. Participants is chosen based on suggestions by the shelter's administration and their consent for interviews. Thematic analysis will be carried out to identify the main theme to the psychosocial adjustments of the behavior, social, emotions and mental health.

\section{Implication and Recommendation For Future Research}

The implications of the research are for the care services and victimizes children's rehabilitations. The findings of this study will contribute towards psychosocial adjustments of the RKK residents through improvement of care and help services based on the children's specific needs. The RKK administrations could also share the information about the institution in collaboration with the community to increase awareness and positive acceptance of the care and protection institutions' residents. It is hoped that the findings of this study will be of benefit to those involved as a reference to identify factors that contribute towards healthy psychosocial development of the residents. 
As a suggestion for future studies, different contexts and settings apart from the instituons should be taken into consideration. Apart from that, similar studies are needed to explore their psychosocial adjustments in the outside environment when they leave the care and protective institutions.

\section{Conclusion}

In conclusions, through the study conducted, the residents receive equal rights in various areas including education through involvement in various activities, learning facilities, teaching and better career prospects. The residents of the institutions can also move freely as the members of the society and are able to choose preferred carerr in the future. Positive acceptance from the society is necessary as psychosocial adjustments will then take place smoothly. If unrecognition or negative perceptions from the society occurs, these children will feel left out and they will be unable to adapt successfully due to stress and low self appreciation.

\section{References}

Abd. Manaf, A. R., \& Mokhtar, N. (2013). Social support for child abuse cases in institutional care. Journal of Social and Development Sciences, 4(11), 508-513.

Abd. Rahman, F. N., Mohd Daud, T. I., Nik Jaafar, N. R., Shah, S. A., Tan, S. M. K., \& Wan Ismail, W. S. (2013). Behavioral and emotional problems in a Kuala Lumpur children's home. Pediatrics International, 55(4), 422-427. Retrieved from http://doi.wiley.com/10.1111/ped.12115

Almas, A. N., Degnan, K. A., Walker, O. L., Radulescu, A., Nelson, C. A., Zeanah, C. H., \& Fox, N. A. (2015). The effects of early institutionalization and foster care intervention on children's social behaviour at age 8 . Social Development, 24(2), 225-239. https://doi.org/10.1080/19386389.2015.1099967.Transforming

Bruskas, D., \& Tessin, D. H. (2013). Adverse childhood experiences and psychosocial well-being of women who were in foster care as children. Nursing Research and Practice, 17(3), 131-41. https://doi.org/10.7812/TPP/12-121

Chan, C. C. (2013). A comparative study on Rumah Kanak-Kanak (Children Residential Home) and Rumah Tunas Harapan (Foster Home) in Malaysia: A child centric perspective. (Unpublished doctoral dissertation). National University of Singapore.

Fonagy, P. (2018). Attachment theory and psychoanalysis. Routledge.

Fonagy, P., \& Campbell, C. (2016). Attachment theory and mentalizing, 1-25. Retrieved from http://discovery.ucl.ac.uk/1476997/1/Fonagy_Revisions_Attachment Theory and Mentalizing.pdf

Glantz, T., \& Gushwa, M. (2013). Reflections on Foster Youth and Education: Finding Common Ground. Reflections, 19(4), 15-23. from http://proxy.binghamton.edu/login?url=http://search.ebscohost.com/login.aspx?direct=true\&db=sih\&AN=1 10145136\&site=ehost-live

Henrichon, S. J. (2016). Foster Care Students and Academic Success : A Case Study. Northcentral University, Arizona.

Koizumi, M., \& Takagishi, H. (2014). The relationship between child maltreatment and emotion recognition. PloS One, 9(1), 1-4. https://doi.org/10.1371/journal.pone.0086093

Mokhtar, N. (2015). Sokongan psikososial bagi kanak-kanak yang didera secara seksual di Rumah Kanak-Kanak, Jabatan Kebajikan Masyarakat. (Unpublished doctoral dissertation).Universiti Utara Malaysia.

Morton, B. M. (2015). Barriers to academic achievement for foster youth: The story behind the statistics. Journal of Research in Childhood Education, 29, 476-491. https://doi.org/10.1080/02568543.2015.1073817

Nalasamy, P. R., \& Ah, S. H. A. B. (2013). Hak kanak-kanak dalam jagaan institusi awam. Kuala Lumpur: Universiti Malaya.

Raj, S. P., \& Raval, V. V. (2013). Residential child care in Malaysia: An exploratory qualitative study of caregiverchild interactions. International Perspectives in Psychology: Research, Practice, Consultation, 2(3), 194206. https://doi.org/10.1037/a0032751

Renfree, S. T., Mcdermott, J. M., Nelson, C. A., Zeanah, C. H., \& Fox, N. A. (2015). The effects of early foster care intervention on attention biases in previously institutionalized children in Romania. Developmental Science, 18(5), 713-722. https://doi.org/10.1111/desc.12261

Schmidt, J., Miranda Cunningham, Dalton, L. D., Powers, L. E., Geenen, S., \& Orozco, C. G. (2013). Assessing restrictiveness: A closer look at the foster care placements and perceptions of youth with and without disabilities aging out of care. Journal of Public Child Welfare, 7(5), 586-609. https://doi.org/10.1016/j.micinf.2011.07.011.Innate

Soares, I., Belsky, J., Oliveira, P., Silva, J., Marques, S., Baptista, J., \& Martins, C. (2014). Does early family risk and current quality of care predict indiscriminate social behavior in institutionalized Portuguese children? 
Attachment and Human Development, 16(2), 137-148. https://doi.org/10.1080/14616734.2013.869237

Wahab, S., Tan, S. M. K., Marimuthu, S., Razali, R., \& Muhamad, N. A. (2013). Young female survivors of sexual abuse in Malaysia and depression: What factors are associated with better outcome? Asia-Pacific Psychiatry, 5, 95-102. https://doi.org/10.1111/appy.12051

Yampolskaya, S., Mowery, D., \& Dollard, N. (2014). Profile of children placed in residential psychiatric program: Association with delinquency, involuntary mental health commitment, and reentry into care. The American Journal of Orthopsychiatry, 84(3), 234-43. https://doi.org/10.1037/h0099808 